\title{
Introducing a food program to increase muscle mass power in a high school baseball club: perception of players and guardians
}

\author{
Tokie Izaki ${ }^{*}$, Kazue Yamamoto ${ }^{2}$ \\ From International Society of Sports Nutrition: 8th Annual ISSN Conference and Expo \\ Las Vegas, NV, USA. 24-25 June 2011
}

\section{Background}

In Japan, many baseball clubs have been trying to increase players' food intake so that players could increase muscle mass power to obtain better performance. Ways to do this have included increasing protein intake and eating between meals. It is also common in Japan to provide players with a food program which encourages them to eat as much food as they can for 5-7 day. The aim of this supervised program is to increase their food consumption. However, one possible risk is that players develop a strong loathing for food. Therefore, this study targeted the perceptions of players and guardians about a food program.

\section{Methods}

A 10 day food program was introduced by coaches at a high school baseball club. For 10 days, only during lunch time (50-60 minutes), players were under an obligation to eat as much food as they could (mainly carbohydrates, in addition to a lunch box (500-600 cal). A questionnaire was administered to high school baseball players $(n=43)$ and their guardians $(n=43)$ to explore how they perceived the amount of food, the change of their food intake and weight (e.g., height $172.37 \mathrm{~cm}$, weight $66.75 \mathrm{~kg}$ on average) and what they thought of the program overall.

\section{Results}

Almost $82 \%$ of players reported that the amount of food intake was too much. Regarding the change of weight after the food program, 63\% of players (increased $1900 \mathrm{~g}$ on average, according to players' self-report) and 53\% of guardians reported 'changed successfully'. Regarding the amount of food intake after the program, $62 \%$ of players and $55 \%$ of guardians reported 'increased'. Guardians commented that players realized what amount of food they should intake (43\%). Some guardians also explained that enjoying food was not something they paid attention to $(13 \%)$.

\section{Conclusion}

The majority of players were interested in increasing their weight. Guardians found that it was often difficult to find time to provide this kind of opportunity. Therefore, most players and guardians commented about the program positively. However, there were many considerations related to this intervention such as needing to pay more attention to body fat percentage, muscle mass and the contents of food.

\section{Acknowledgements}

The authors appreciate for all students and coach who participated with this study.

\section{Author details}

'Department of Human Development and Education, Tokaigakuen University, Nakahira Tenpakuku 2-901, Nagoyashi Aichiken 468-8514, Japan. ${ }^{2}$ Nagoya City University, Graduate School of Natural Sciences. Yamanohata 1, Mizuhocho Mizuhoku Nagoyashi 467-8501, Japan.

Published: 7 November 2011

doi:10.1186/1550-2783-8-S1-P11

Cite this article as: Izaki and Yamamoto: Introducing a food program to increase muscle mass power in a high school baseball club: perception of players and guardians. Journal of the International Society of Sports Nutrition 2011 8(Suppl 1):P11.

\footnotetext{
* Correspondence: izaki-@@tokaigakuen-u.ac.jp

'Department of Human Development and Education, Tokaigakuen

University, Nakahira Tenpakuku 2-901, Nagoyashi Aichiken 468-8514, Japan

Full list of author information is available at the end of the article
}

( 2011 Izaki and Yamamoto; licensee BioMed Central Ltd. This is an open access article distributed under the terms of the Creative 